\title{
2 Understanding Indicators And Monitoring For Sustainability In The Context Of Complex Social-Ecological Systems
}

\author{
L. Jamila Haider, Alvaro Iribarrem, Toby Gardner, Agnieszka E Latawiec, \\ Helena Alves-Pinto, Bernardo Strassburg
}

\subsection{Introduction}

It is widely accepted that ecosystems across the world are increasingly affected by humans. Many earth system scientists contend that we have entered a new geological epoch, the Anthropocene, in which humans exert a dominating influence on many key earth system processes (Crutzen, 2002; Steffan et al., 2007; Rockström et al., 2009). Research on the characteristics of this new era emphasizes that a) the world is interconnected and thinking of a given study system as being made up of both social and ecological attributes that interact in complex and adaptive ways can help us make sense of these interactions; and b) the speed of environmental change introduces novel institutional challenges, such as the need to grapple with cross-scale interactions where the activities of one community or society can have far reaching effects on another, thousands of kilometers away (Galaz, 2014 pp: 15). This perspective provides the starting point for why and how, in our view, sustainability indicators should be developed in a way that takes account of the complex and continuously changing nature of the systems they are trying to assess.

This chapter begins with a general introduction to some of the key concepts that have emerged from thinking about complex adaptive systems. These concepts highlight some of the considerations that should underpin any attempt to monitor changes in a set of focal attributes that cannot be disentangled from the wider system within which they exist. We then provide a brief introduction to socialecological systems thinking that explicitly recognizes the highly interdependent and cross-scale nature in which social and ecological attributes of a system are often connected. We posit that social-ecological systems thinking can provide invaluable guidance in designing monitoring and evaluation systems for assessing how different (interconnected) social and ecological attributes of a system are changing as we monitor progress towards, or away from, sustainability. In adopting such a systems approach we conclude with a discussion on the ways in which sustainability indicators themselves, as interdependent parts of the system they are designed to measure, can ultimately change perceptions of values and goals (for better or worse) regarding how that system should be managed. 


\subsection{Complex Adaptive Systems: The Whole Is Larger Than The Sum Of Its Parts}

How does a framing of complex adaptive systems help us manage systems for change? First, by framing the 'things' we study as systems, we can set a boundary on what interactions we wish to analyse, monitor or change. A systems framing implies that cross-scale interactions are interdependent and understanding only one interaction in isolation from others will not provide an adequate explanation of the dynamics we seek to understand and influence. Further, adopting a systems perspective can help identify ways in which an isolated focus on monitoring and managing a single, or small number of attributes (e.g. human wellbeing, environmental health), can result in undesirable or even perverse outcomes, such as poverty traps (Carpenter and Brock, 2006).

A complex (versus a simple) system means that there are many working parts, and that many of these parts are connected through positive (reinforcing) or negative (balancing) feedbacks. Moreover, a complex system interacts across multiple spatial and temporal scales and is constantly changing and adapting in response to new pressures and influences, whether they be endogenous or exogenous. Complex adaptive systems (CAS) therefore have emergent non-linear properties, which make them unpredictable and subject to runaway feedback processes. Such a perspective reveals a number of properties that can help characterize the complex and interdependent relationships between humans and the environment in which we live, and which are typical of many landscapes around the world. Recognizing these general properties can help in design, implementation and interpretation of monitoring and evaluation processes to help foster progress towards sustainability.

a) CAS are highly unpredictable: Component parts of a system are connected in diverse ways and relationships are non-linear. This means that systems can approach and pass critical thresholds (or tipping points), beyond which system characteristics fundamentally change. For example, Lenton et al. (2008) and Lenton and Williams (2013) have identified nine potential policy-relevant tipping points in the Earth's climate system. One specific example is the dieback of the Amazon rainforest, which will have global effects on moisture recycling and carbon sequestration, and there is great uncertainty about how this may have far reaching effects on global climate patterns.

b) CAS can be contagious: what happens in one part of the system can have cascading, reinforcing or balancing effects on other parts of the system across various scales. For example, West Africa's monsoon shift may lead to a change in the greening of the Sahara desert.

c) CAS demonstrate modularity and redundancy: parts of the system are more connected within, rather than between nodes, and some repeat themselves. This means that CAS possess cross scale dynamic properties and indicators must be appropriately aligned to capture these processes. For example, some species may 
play the same ecosystem function, and therefore have functional redundancy. This is incredibly important in the face of an unexpected event, a pest outbreak for example, and the existence of various species that carry out the same function can help maintain the function of the ecosystem.

d) CAS can self-organise: the direction of the trajectory depends on the system's history and initial conditions. Birds flocking is a typical example of a selforganising system.

These properties together help make up the general resilience of the system. Resilience is the capacity of social-ecological systems to continually change and adapt yet retain the same basic structure, composition and function (Folke et al., 2010). Resilient social-ecological systems have the potential to sustain development by responding to and shaping change in a manner that does not erode the possibility of exploiting future opportunities (Berkes et al., 2003). Resilience used in this general way has taken a prominent role in sustainability discourse. It is important to note that resilience is also characterized as the way in which a particular system responds to a perturbation. In this case, resilience is not inherently a good thing, and requires a normative judgment on which aspects of a system should persist in the face of change, adapt to unexpected surprise or actively transform into a new system configuration. Meanwhile, notions of sustainability emphasise the importance of fostering improvements in social wellbeing without undermining the critical environmental processes and services upon which the wellbeing of future generations depends. As such the two concepts should be seen as compatible rather than contradictory, as an understanding of social-ecological resilience can help in understanding the challenges and opportunities facing more sustainable development trajectories.

Any given study system is made up of multiple subsystems, and measuring or understanding changes in attributes of just one subsystem will not allow for an adequate representation of the wider system, and may lead to inappropriate or even maladaptive management practices. The characteristics of complex adaptive systems have profound implications for how we manage them and management processes can be improved by making them sufficiently adaptable and flexible that they can deal with uncertainty and surprise (Berkes et al., 2003).

\subsubsection{Social-Ecological Systems}

Thinking about social-ecological systems as a type of complex adaptive system arose from the growing understanding that social and ecological systems are inherently linked (Berkes et al., 2001). Coral reefs which are seemingly undisturbed by any direct interaction with humans might be affected by climate change, ocean acidification and sea level rise - all driven, in part, by the activities of humans in distant places and earlier time periods. Or likewise, urban dwellers, who have little direct contact 
with many natural resources, are critically dependent on ecosystem services like the provision of clean and plentiful water from upstream watersheds, clean air and cultural services such as the conservation of urban biodiversity in parks and recreation areas. Seen like this, nearly everything can be viewed as a social-ecological system, and understanding and monitoring the interactions between interconnected and interdependent systems is essential for achieving lasting and large-scale sustainable development goals.

The framing of social-ecological systems has also helped create a common metatheoretical framework for scholars from across disciplines to engage in a meaningful way about the management of natural resources (e.g. Ostrom 2009; Poteete et al., 2010). The most recent work by Elinor Ostrom for example (2007; 2009) has adopted a social-ecological approach, tying together institutional scholars, sociologists, ecologists and practitioners with a framework that spans across disciplines and fields.

\subsection{How Can Social-Ecological Systems Thinking Help In The Design Of Sustainability Indicators?}

The proposition put forward by this chapter is that a systems approach is extremely useful in providing the perspective and context necessary for designing indicators that can provide transparent information on progress towards, or away from sustainability. Nevertheless, the very nature of complex social-ecological systems, with defining non-linear and cross-scale dynamics makes this task far from trivial. Here we posit four overarching and interrelated principles that can help guide researchers and practitioners in the design of indicators for sustainability.

\section{Principle 1. Indicators are integral parts of a wider monitoring and management system}

Indicators provide the key tool by which different elements of the monitoring and evaluation process can be logically connected to a given management regime. Discussions around indicators are often held out of context to the monitoring and management system to which they are intended to contribute. The connections are often implicit. The information provided by indicators is only of value if it feeds into a monitoring process managed by credible, legitimate and empowered individuals or institutions that are, in turn, connected to a system of resource management or policy design that is responsible for fostering progress towards sustainability. This is true whether the system is the entire world, such as the case of the Living Planet Index (managed by WWF and used as a key indicator of the status of biodiversity for a range of UN processes and conventions), or a specific conservation area, urban park, or conditional agricultural aid program. The ability to gather information that captures how valued attributes are changing over time, and in response to different 
interventions or pressures, is widely viewed as a key condition for the sustainable management of common pool resources, including water, fisheries, many timber and fuel-wood resources (Ostrom, 2009; Danielsen et al., 2013).

\section{Principle 2. Indicators should be designed and used in combination with a suite of other indicators as a coherent part of a wider monitoring system}

Despite the tantalizing appeal of a single magical index that can provide an adequate barometer of progress towards sustainability, the complex nature of social-ecological systems means that such an index does not, nor will ever, exist (see also section 4 below, and chapter 1). Instead, indicators can only have relevance to management and decision making processes when they are used in conjunction with other, related indicators, and in the context of a particular aim or objective (e.g. Niemi and McDonald, 2004 in the case of biodiversity). That said, the way in which indicators are combined is central to determining the value of the information they provide. Many environmental monitoring programs, for example, combine various types of indicators into uncoordinated simple lists, suggesting that they should be measured and reported together, and with little hierarchical or interactive structure (Kneeshaw et al., 2000; Rempel et al., 2004; Gardner, 2010). This is partly due to the superficial surveillance function that many environmental assessment programs play, with few if any incentives or hard laws motivating or obligating that they are designed in a more coherent and useful way (Lindenmayer et al., 2010). Some outcome level variables are assessed in isolation of any other indicators as a form of surveillance monitoring. This can provide a valuable function as an early warning system or "canary in the coal mine" that something is wrong. However, unless they are also linked to both indicators of how the system is managed, and background pressures and drivers, then it can be impossible to decipher why an observed change has taken place. In turn, it is also then impossible to determine how the information gained from a change in indicator value can be used to alter how the system is managed in some way, and protect the attributes that are the underlying source of concern.

To be effective in contributing with useful and coherent information for management and policy design, it is useful to consider two main types of indicators; those whose function is prescriptive, and those whose function is evaluative. Management policy and process indicators are both prescriptive in that they are used to measure or verify the existence or implementation of certain policies and management strategies. Whilst they only serve to prescribe a rule or norm they are nevertheless essential in ensuring that measurements of actual change in outcome level variables are linked to formal or de facto decision-making bodies and processes. These may include indicators like the cutting schedule of a managed forest, the sewage processing requirements for discharge into natural rivers, or social safeguards requiring the employment of a certain number of local people in an oil palm plantation.

By contrast, performance indicators are evaluative in the literal sense that they are used to evaluate changes in management performance and are made up of 
outcome level variables that are proxies of changes in the actual valued attributes of a system. These may include measures of social wellbeing such as education, health and income distribution, or environmental measures such as water quality indices or proxies of biodiversity. It is important to note that performance indicators can also be qualitative, such as an expert based scoring of air quality or worker satisfaction, where quantitative data are either unavailable or inappropriate.

\section{Principle 3. It is essential to understand how different indicators relate to the wider system that is being monitored}

Nothing exists in isolation and it is only ever possible to assess and monitor a small number of indicators that, in turn, relate to a tiny number of attributes and processes in the wider study system. Faced with such complexity it is very useful to develop a conceptual model to visually depict how the system of interest (be it a city's water supply, managed wetland or system of national environmental accounts) is understood to be structured and function. Part of this conceptual model are the indicators of management interest, while the remainder depicts other system attributes and processes that may not be of direct concern, and may not all be measured, but which may influence or mediate changes in the valued attributes and indicators. These influences should encompass both immediate pressures - "fast” variables" - but also drivers that can play out over much longer timescales but which may ultimately have an overriding effect on system dynamics - so-called "slow" variables (Gunderson and Holling, 2002).

As an example we can think of the mechanism for land-based climate change mitigation activities that is REDD+: Reducing Emissions from Deforestation and Degradation. Distinct from some other climate mitigation mechanisms, REDD+ interventions act upon a complex and dynamic social-ecological system that operates across different interconnected land-uses, scales, time horizons, management sectors, governance arrangements and types of authority (Fig. 1). Although REDD+ is focused on the protection and enhancement of terrestrial carbon stocks (Fig. 1) the primary indicator of concern - any REDD+ intervention will be both influenced by, and have unavoidable impacts on the provision of other (non-carbon) ecosystem services, in addition to having other social welfare implications. Ignoring these first and second order relationships and feedbacks would risk serious perverse outcomes that have plagued conservation interventions in the past (Parotta et al., 2012). Risks may include the displacement of deforestation to carbon poor but biodiversity rich regions and the potential for elite capture of any social and financial benefits provided by REDD+ (Parotta et al., 2012). These unintended consequences also have the potential to undermine the long-term sustainability of emissions-reduction targets by degrading social and ecological resilience. For example, forests that are protected from direct human impacts but host an impoverished biodiversity due to over-hunting of game animals may experience a shift in species composition towards more wind- 


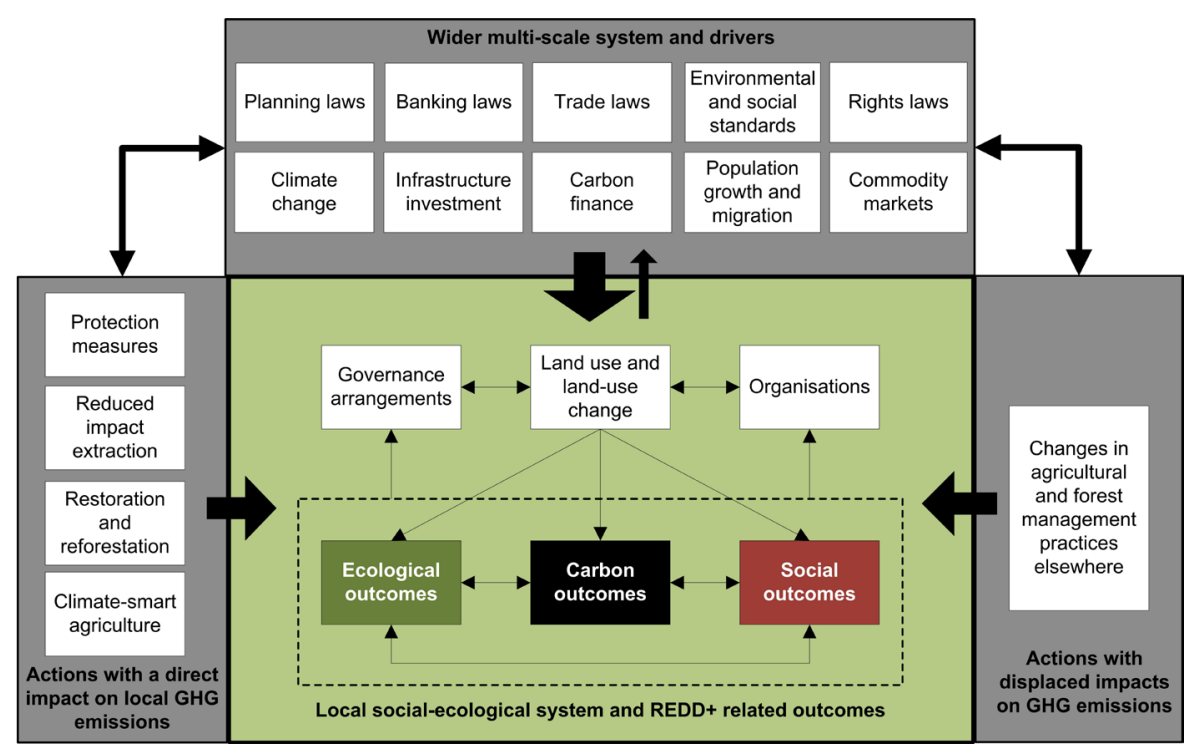

Figure 1: Conceptual figure of REDD+ consequences and effects operates across different interconnected land-uses, scales, time horizons, management sectors, governance arrangements and types of authority.

dispersed and low-density trees. Socially unjust REDD+ interventions are likely to suffer reductions in community engagement, undermining the long-term viability of an emissions reduction program and potentially leading to social unrest. For more information on indicators for REDD+ implementation see chapter 4.

Principle 4. Indicators, and the monitoring and management systems to which they are linked, should be designed through a participatory process that involves the key stakeholders who are responsible for, or influenced by the system attributes that sustainability indicators are trying to represent

In all the debate about the purpose and practicalities of sustainability indicators and monitoring it is easy to forget the importance of people in every part of the equation. It is people who design and implement indicators and monitoring activities, people who draw conclusions from sample data, people who decide which findings will be listened to and incorporated into new policies and management approaches onthe-ground and which will be discarded, and people who decide whether efforts to measure changes in a particular indicator are ultimately worthwhile and should be sustained into the long-term.

Participatory approaches to monitoring sustainability indicators are particularly relevant in developing countries, where meaningful engagement in the design and execution of monitoring programs by local people can empower them to take responsibility for the management of their own resources. It can also encourage a 
culture of learning which is key to the success of adaptive management (Cundill and Fabricius, 2009). In turn this empowerment and enhanced proximity between monitoring and management activities can often lead to more rapid and effective decision-making (Danielsen et al., 2007). A successful example of participatory indicator development and monitoring is Tebtebba, a global indigenous organization that works to incorporate indigenous rights, social justice and environmental sustainability into international processes. Their work on indicators is particularly impressive as diverse groups of indigenous peoples identify what they value and this is later aggregated at a higher scale (Chavez and Tauli-Corpuz, 2008).

\subsection{Sustainability Indicators As Interdependent Components Of The Social-Ecological Systems They Are Designed To Measure}

No sustainability indicator exists independently of the social-ecological system it is designed to assess. As a consequence, differences in context in which an indicator is assessed can result in markedly different outcomes (Meadows, 1998). For example, a recycling initiative in Poland based on leaflets and TV commercials directed at individual households had relatively little positive effect on individual behavior and recycling levels remained low. In an effort to increase recycling, incentives were introduced at the level of entire condominiums. Under this new monitoring regime the entire community was rewarded if everybody recycled, and through increased visibility among members of the community and concerns that individuals who failed to recycle would be socially ostracized, the recycling rates increased.

Over-emphasis on achieving changes in the value of a particular indicator or set of indicators can detract attention away from the underlying societal values it is intended to measure. As such, efforts to optimize management and decision-making processes to improve the value of an indicator can result in the indicator becoming the target in its own right. Further, because indicators can only ever provide a simplified and limited representation of the complex and dynamic social and environmental conditions they are designed to measure, placing excessive emphasis on changing the values of an indicator can lead to important changes being masked and allowing potentially perverse and unintended outcomes to emerge. As discussed above there are many reasons why indicators, for reasons of practicality are often highly simplified proxies of the attributes that managers and policy makers are really trying to change. An example discussed elsewhere in this book (chapter 8) is in the case of ecological restoration. The past few years have seen a marked increase in recognition of the need to restore large areas of native habitat if ecosystem services critical to human wellbeing - including hydrological, pollination and pest control services - are to be maintained and restored. The Aichi Target 15 of the United Nations Convention on Biological Diversity together with the 'Bonn Challenge', a global initiative on restoration, have established the goal to restore 150 million hectares of degraded and 
deforested land globally by 2020 (Menz et al., 2013). However, a target based only on hectares is not sufficient to indicate the successful restoration of the ecosystem services that underpin political support for this action - instead it is also necessary to take account of the condition of regenerating and planted forests, including aspects of their structural, compositional and functional diversity (see chapter 8) (Van Bellen, 2002; McGlade, 2009).

If employed for long enough, indicators can ultimately change underlying perceptions of values, becoming valued attributes in their own right often without a clear understanding of why changes in their value are more or less desirable for society. As eloquently stated by Meadows (1998), although indicators are formulated to measure what we value, in practice the opposite also often happens - we come to value what we measure. One of the most famous and instructive examples of this phenomenon can be found in the case of Gross Domestic Product (GDP) and how its use has resulted in entire economies being continuously shaped and reshaped to increase their value, often at the expense of critically important economic, social and environmental attributes (Daly, 2005).

\subsubsection{Indicators And The Changing Nature Of Value: The Case Of Gross Domestic Product (GDP)}

As discussed earlier in this chapter, an indicator is not inherently good or bad: its influence on how we manage social-ecological systems depends on the context in which it is measured and interpreted as well as the underlying objectives. Problems emerge when an indicator is interpreted as providing more meaning than was originally intended or than it is capable of providing. For example, a country's development standing is perceived principally not through indicators of equitable distribution of wealth, high literacy or low infant mortality rates, but rather on account of a high GDP. Marked changes in GDP readily make headline news of national newspapers around the world and can have a significant effect on determining the success or failure of a political party at election times. Many national and international (e.g. European Union) government policies are explicitly designed to achieve increases in GDP (Costanza et al., 2014).

GDP is designed to measure economic productivity and can be simply defined as the total monetary value of everything that has been produced in a given period (Stiglitz et al., 2010; Veiga, 2010). It is this intuitive and simple meaning that underpins its attraction to policy makers the world over. On the one hand GDP itself is not a useless measure - understanding the total value of a countries' economic output is extremely useful as it is a proxy for a host of factors that most societies care about - such as the amount of tax revenues that are being generated. However, there are fundamental limitations to its application and use that continue to remain poorly appreciated despite its growing notoriety. 
Whilst on the one hand GDP calculations are supported by detailed economic data and transparent methods (Tayra and Ribeiro, 2006; Bauler et al., 2009; Moldan and Dahl, 2009), the inclusion of certain economic activities and goods into its calculations is subject to country-dependent choices, and decisions about what should be valued. As such, critiques of GDP have a ready list of undesirable economic activities that do or could have a marked influence on levels of GDP. For example, a recent study pointed out the United Kingdom's GDP would be up to 5 percent higher if activities such as illegal prostitution and drugs were counted (Pilling, 2014). Another example is where the cost of crime protection is taken into account in GDP, which therefore rises when levels of violence increase across the country (Van Bellen, 2002; Tayra and Ribeito, 2006; Costanza et al., 2014).

In addition researchers and policy makers have long recognized that a single indicator such as GDP is inherently incapable of capturing the myriad attributes that contribute towards the sustainability of a country's development, and is blind to many negative social and environmental changes (Bauler et al., 2009). In particular, the focus of GDP on consumption rates means that it is naive to the many environmental and social benefits that contribute towards human wellbeing yet are rarely, if ever, quantified in monetary terms (Tayra and Ribeito, 2006; Stiglitz et al., 2010), and that this naivety underpins the increasingly widespread assumption that the current pattern of economic growth is unsustainable (Dasgupta and Ehrlich, 2013).

\subsubsection{Towards Alternative Measures Of Sustainable Human Prosperity}

There is a large number of efforts to complement or entirely replace GDP with indicators that can offer a more nuanced and transparent barometer of progress towards, or away from sustainable development. Set against these efforts is the fact that the very concept of sustainable development is, to the persistent frustration of many sustainability practitioners and decision makers, hard to reach a consensus on, much less measure progress towards. The most enduring definition can be traced to the Brundtland Report (WCED, 1987) where sustainable development is defined as human development that "meets the needs and aspirations of the present without compromising the ability of future generations to meet their own needs." Central to the common interpretation of this concept is the need to reconcile environmental, social and economic demands, and recognition that the existence of biophysical limits or boundaries, together with imperatives of social equity, justice and wellbeing that cannot be breached if economic growth is to be considered sustainable (e.g. Ehrlich and Ehrlich, 2013).

Many alternative indicators of human prosperity to GDP are biased towards only one or two of the three "pillars" (social, environmental, economic) of sustainable development. These can be divided in three groups, of which the first reflects social and environmental factors; the second includes subjective measures of wellbeing; and 
the third includes dimensions of wellbeing related to housing, leisure, life expectancy, among others (Costanza et al., 2014).

The Human Development Index is one of the most widely recognized measures of development that considers many of the same variables included in GDP but also includes measures of human longevity and education (Wilson et al., 2007; Guimarães and Feichas, 2009). By contrast, the Ecological Footprint index is focused on measuring environmental impacts, and the sustainability of human consumption patterns by calculating the amount of resources that are required to support consumption (and the production of waste) (Wilson et al., 2007; Stiglitz et al., 2010). The Genuine Progress Index (GPI) tries to go one step further by considering not only economic (spending, consumption), but also social and environmental criteria (aspects of wellbeing, deduction of environmental factors such as pollution from consumption, and loss of natural resources, among others) (Stiglitz et al., 2010). Despite its more inclusive approach GPI remains problematic in a number of key aspects, with the valuation of externalities considered to be too speculative (Veiga, 2010), and many of the criteria being difficult to collect data for (Guimarães and Feichas, 2009).

While all of these measures seek to capture some aspect of human prosperity the fact that they emphasize different aspects, and entirely exclude others, often leads to contrasting trends, confounding interpretation and leading to conflicting guidance for policy makers (Veiga, 2010). Disparities are clear when comparing patterns of GPI and GDP over time, revealing that GDP can rise at the same time that GPI is falling, revealing ongoing environmental degradation (Guimarães and Feichas, 2009) and widening social inequality (Tayra and Ribeiro, 2006).

As most of the alternative indicators to GDP are biased toward one or two pillars of sustainability and not on the links between them (Moldan and Dahl, 2009) they continue to fall short of providing a clear and robust picture of changes in the overall system. Appreciation of the need to draw on a suite of indicators rather than one single "magical index" (see section 2 above) underpin the significant efforts that are being invested in the crafting of the United Nations Sustainable Development Goals (SDGs) in the aftermath of the Rio+20 conference and to drive the post 2015 international development agenda (see Introduction to this book). The SDGs are designed to be "action-orientated, concise and easy to communicate" whilst also being comprehensive enough to address all major sustainability concerns.

\subsection{Conclusions}

A systems perspective can be very helpful in designing indicators and monitoring programs. We propose four principles in designing and monitoring sustainability indicators for social-ecological systems: i) indicators are integral parts of a wider monitoring and management system, ii) indicators should be designed and used in combination with a suite of other indicators as a coherent part of a wider monitoring 
system, iii) it is essential to understand how different indicators relate to the wider study system, iv) indicators, and the monitoring and management systems to which they are linked should be designed through a participatory process that involves the key stakeholders who are responsible for, or influenced by the system attributes that sustainability indicators are trying to represent. Indicators will always remain a subjective reflection of the varying goals and values that different societies and groups of stakeholders hold. Indicators will also inevitably become part of the complex system themselves, and as such changes in their values may result in changes to societies' values. There is an urgent need for systems thinking to become much more mainstreamed in both research and policy spheres if the indicator and monitoring systems we depend upon are to provide a reliable barometer of progress towards a more sustainable world.

\section{References}

Bauler, T., Douglas, I., \& Daniels, P., et al. (2009). Identifying methodological challenges. In T. Hák, B. Moldan \& A. L. Dahl, (eds), Sustainability Indicators: A Scientific Assessment. Washington, DC: Island Press (SCOPE Series).

van Bellen, H. M. (2002). Indicadores de Sustentabilidade: Uma análise comparativa. Tese (Doutorado em Engenharia de Produção) - Curso de Pós-Graduação em Engenharia de Produção, Universidade Federal de Santa Catarina. Santa Catarina.

Berkes, F., Colding, J., \& Folke, C. (2003). Navigating social-ecological systems: Building resilience for complexity and change. Cambridge, UK: Cambridge University Press.

Berkes, F., Mahon, R., \& Mcconney, P., et al. (2001). Managing small-scale fisheries: alternative directions and methods. Ottawa, Canada: IDRC.

Carpenter, S. R., \& Brock, W. A. (2008). Adaptive capacity and traps. Ecology and Society, 13(2), 40

Chavez, R. de, \& Tauli-Corpuz, V. (eds.). (2008). Guide on Climate Change \& Indigenous Peoples. Filipinas: Tebtebba Foundation.

Crutzen, P.J. (2002). Geology of mankind. Nature, 415, 23. doi: 10.1038/415023a

Cundill, G., \& Fabricius, C. (2009). Monitoring in adaptive co-management: Toward a learning based approach. Journal of Environmental Management, 90, 3205-3211.

Costanza, R., Kubiszewski, I., Giovannini, E., et al. (2014). Development: time to leave GDP behind. Nature, 505, 283-285.

Daly, H. E. (2005). Economics in a full world. Scientific American, 293(3), 100-107.

DANielsen, F., Adrian, T., Brofeldt, S., \& NoORdWiJK, M. VAn, et Al. CoMmunity Monitoring for REDD+: INTERNATIONAL PROMISES AN D FIELD REALITIES. ECOLOGY AND SOCIETY 18(3), 41P.

Danielsen, F., Mendoza, M.M., \& TAgtag, A. (2007). InCreasing Conservation Management Action by Involving Local Stakeholders in Natural ResourCe Monitoring. Ambio, 36, 566-570.

Dasgupta, P. and Ehrlich, P. (2013). Pervasive Externalities at the Population, Consumption, and Environment Nexus. Science, 340, 324-328.

Ehrlich, P, and Ehrlich, A. (2013). Can a collapse of global civilization be avoided Proceedings of the Royal Society of London B: Biological Sciences, 280(1754), 20122845.

Folke, C., Carpenter, S. R., \& Walker, B. H., et al. (2010). Resilience thinking: integrating resilience, adaptability and transformability. Ecology and Society 15(4), 20p.

Gardner, T. (2010). Monitoring Forest Biodiversity: Improving conservation through ecologicallyresponsible management. Earthscan Ltd. London. 
Galaz, V. (Ed.) (2014). Global environmental governance, technology, technology and politics: The Anthropocene gap. Edward Elgar Publishing. Chicago.

Guimarães, R.P., \& Feichas, S.A.Q. (2009). Desafios na construção de indicadores de sustentabilidade. Ambiente \& Sociedade, 12(2), $307-232$.

Gunderson, L. H., \& Holling, C. S. (eds.). (2002). Panarchy: understanding transformations in human and natural systems. Washington, D.C: Island Press.

Kneeshaw, D.D., Leduc, A., \& Drapeau, P., et al. (2000). Development of integrated ecological standards of sustainable forest management at an operational scale. Forestry Chronicle, 76, 481-493.

Lenton, T.M., Held, H., \& Kriegler, E., et al. (2008). Tipping elements in the Earth's climate system. PNAS, 105(6), $1786-1793$.

Lenton, T.M., \& Williams, H.T.P. (2013). On the origin of planetary-scale tipping points. Trends Ecology, $28,380-382$.

Lindenmayer, D.B., Likens, G., \& Franklin, J. (2010). Rapid responses to facilitate ecological discoveries from major disturbances. Frontiers in Ecology and the Environment, 8, 527-532.

Meadows, D.H. (1998). Indicators and Information Systems for Sustainable Development. Hartland Four Corners VT: Sustainability Institute.

Menz, M.H.M., Dixon, K.W., \& Hobbs, R.J. (2013). Hurdles and opportunities for landscape-scale restoration. Science, 339, 526-527.

McGlade, J. (2009). Foreword: Finding the Right Indicators for Policymaking. In T. Hák, B. Moldan \& A. L. Dahl, (eds), Sustainability Indicators: A Scientific Assessment. Washington, DC: Island Press (SCOPE Series).

Moldan, B., \& Dahl, A.L. (2009). Challenges to Sustainability Indicators. In T. Hák, B. Moldan \& A. L. Dahl, (eds), Sustainability Indicators: A Scientific Assessment. Washington, DC: Island Press (SCOPE Series).

Niemi, G. J., \& McDonald, M. E. (2004). Application of ecological indicators. Annu. Rev. Ecol. Evol. Syst., 35, $89-111$.

OSTROM, E. (2007). A DIAGNOSTIC APPROACH FOR GOING BEYOND PANACEAS. PNAS, 104, 15181-15187.

Ostrom, E. (2009). A General Framework for Analyzing Sustainability of Social-Ecological SYSTEMS. SCIENCE, 325(5939), 419-422.

Parrotta, J.A., Wildburger, C., \& Mansourian, S. (eds.). (2012). Understanding Relationships between Biodiversity, Carbon, Forests and People: The Key to Achieving REDD+ Objectives. A Global Assessment Report. Prepared by the Global Forest Expert Panel on Biodiversity, Forest Management, and REDD+. Vienna: IUFRO, 31, 161p.

Pilling, D. (2014). Has GDP outgrown its use? FT Magazine. Available at: http://www.ft.com/intl/ $\mathrm{cms} / \mathrm{s} / 2 /$ dd2ec158-023d-11e4-ab5b 00144feab7de.html\#axzz375UlsVzB. Accessed on Juy 15th, 2014.

Poteete, A. R., Janssen, M. A., \& Ostrom, E. (eds.) (2010). Working Together: Collective Action, the Commons, and Multiple Methods in Practice. Princeton, NJ: Princeton University Press.

Rempel, A. W., Wettlaufer, J. S., \& Worster, M. G. (2004), Premelting dynamics in a continuum model of frost heave. Journal of Fluid Mechanics, 498, 227 - 244.

Rockström, J., Steffen, W., \& Noone, Ket al. (2009). Planetary boundaries: exploring the safe operating space for humanity. Ecology and Society, 14(2), 32p.

SDG. Sustainable Development Goals. (2014). Sustainable development Knowledge Platform. United Nations. Available at: http://sustainabledevelopment.un.org/?menu=1300. Accessed on July $15^{\text {th }}, 2014$.

Steffan, W., Crutzen, P.J., \& McNeill, J.R. (2007). The Anthropocene: Are Humans Now Overwhelming the Great Forces of Nature? Ambio, 36(8), 614-621.

Stiglitz, J., Sen, A., \& Fitoussi, J.P. (2010). Report by the Commission on the Measurement of Economic Performance and Social Progress. Available at: http://www.stiglitz-sen-fitoussi.fr/documents/ rapport_anglais.pdf 
Tayra, F., \& Ribeiro, H. (2006). Sustainability Indicators Models: synthesis and critical evaluation of the main experiences. Saúde e Sociedade, 15(1), 84 - 95.

Veiga, J.E. da. (2010). Indicadores de sustentabilidade. Estudos Avançados, 24(68), 39 - 52.

WCED. World Commission on Environment and Development. Our Common Future. Oxford University Press: New York, 1987.

Wilson, J., Tyedmers, P., \& Pelot, R. (2007). Contrasting and Comparing Sustainable Development Indicator Metrics. Ecological Indicators, 7, 299-314. 